\title{
Rac1/ $\beta$-Catenin Signalling Pathway Contributes to Trophoblast Cell Invasion by Targeting Snail and MMP9
}

\author{
Minghua Fan ${ }^{\mathrm{a}}$ Yongping $\mathrm{Xu}^{\mathrm{a}}$ Fanzhen Hong ${ }^{\mathrm{a}}$ Xiaolin Gao Gang Xin ${ }^{\mathrm{a}}$ \\ Haijie Hong ${ }^{a}$ Lihua Dong ${ }^{a}$ Xingbo Zhao \\ aDepartment of Obstetrics and Gynecology, The Second Hospital of Shandong University, Jinan, \\ bepartment of Obstetrics and Gynecology, Shandong Provincial Hospital Affiliated to Shandong \\ University, Jinan, China
}

\section{Key Words}

Rac1 $\bullet \beta$-catenin $•$ Preeclampsia $•$ Extravillous trophoblasts $\bullet$ Invasion

\begin{abstract}
Background/Aims: Preeclampsia is an idiopathic and serious complication during gestation in which placental trophoblast cells differentiate into several functional subtypes, including highly invasive extravillous trophoblasts (EVTs). Although the cause and pathogenesis of preeclampsia have remained unclear, numerous studies have suggested that the inadequacy of EVT invasion leads to imperfect uterine spiral artery remodelling, which plays a crucial role in the development of preeclampsia. Rac1, or Ras-related C3 botulinum toxin substrate 1 , was found to be a key regulator of the migration, invasion and apoptosis of various tumour cells. Because EVTs share similar invasive and migratory biological behaviours with malignant cells, this study aimed to determine whether the Rac1 signalling pathway affects trophoblast invasion and is thus involved in the pathogenesis of preeclampsia. Methods: We measured the activity of Rac1 and its downstream targets, $\beta$-catenin, Snail and MMP9 in placental tissues from patients experiencing a normal pregnancy and those with preeclampsia. Furthermore, we treated HTR-8/SVneo cells with a shRNA Rac1 vector and the $\beta$-catenin inhibitor IWP2 and explored Rac1 signalling pathway activation as well as the effects of Snail and $\beta$-catenin on trophoblast invasion. Results: In placental samples from patients experiencing a normal pregnancy and those with preeclampsia, active Rac1 levels and MMP9 protein and mRNA levels were significantly decreased in term pregnancy samples compared to early pregnancy samples. Lower levels were found in preeclampsia samples than in normal term pregnancy samples, and these levels significantly declined in severe preeclampsia samples compared with mild preeclampsia samples. Further analyses demonstrated that both Rac1 shRNA and the $\beta$-catenin inhibitor significantly suppressed MMP9 and Snail activation in trophoblasts, thus impairing trophoblast invasion. Notably, silencing Rac1 down-regulated the expression of $\beta$-catenin in HTR-8/SVneo cells, demonstrating that $\beta$-catenin is a downstream
\end{abstract}


effector of Rac1 in trophoblast invasion. Conclusion: Our data suggest that Rac1-mediated activation of $\beta$-catenin might regulate Snail and MMP9 expression subsequently promoting trophoblast invasion in pregnancy.

\section{Introduction}

Preeclampsia, characterized by hypertension and proteinuria after 20 weeks of gestation, complicates $4 \%$ of pregnancies worldwide and is the leading cause of maternal, foetal and neonatal mortality [1]. Divergent opinions exist on the precise mechanism for the primary pathophysiological development of preeclampsia, but the root causes start at the early stage of implantation. It is generally recognized that the placental insufficiency that results from the shallow invasion of EVTs into the maternal decidua and myometrium is specifically associated with preeclampsia [2].

Rac1, a member of the Rho family of small GTPases, acts as a molecular switch to control a wide array of cellular functions. In response to diverse signals, it converts from an inactive GDP-bound form to an active GTP-bound form. Rac1 signaling has been directly implicated in the regulation of cell motility, such as migration and invasion, through regulating membrane protrusions and cell-matrix adhesion [3]. There is evidence that Rac1 signaling pathway activation promotes invasion and metastasis in a variety of cancer cells [4,5], which shares analogous characteristics with EVTs. Studies have also shown that the activity of Rac1 is downregulated in preeclampsia and HELLP syndrome [6], suggesting a potential contribution of Rac1 to placental development. Moreover, the activation of PTGER1 and PTGER4 which serve as mediators of the $\mathrm{PGE}_{2}$-induced migration of first trimester human EVTs can activate Rac1 [7]. A recent study indicated that RhoGDI2, which belongs to a family of Rho guanosine diphosphate dissociation inhibitors, suppressed EVT migration by inhibiting the activation of Rac1 [8]. These collective observations suggest that Rac1 may play a critical role in EVT invasion.

Matrix metalloproteinases (MMPs) are factors that may facilitate trophoblast invasion [9]. Among the MMPs, MMP9 has been extensively investigated for putative roles in early placental implantation [10]. It is a key effector of extracellular matrix (ECM) remodelling that degrades collagens, gelatin, elastin, proteoglycan core proteins, myelin basic protein, fibronectin and fibrillin-1 [11]. In addition, when active MMP9 is overexpressed at the embryo implantation site by human and mouse trophoblasts, it is involved in promoting invasive behavior $[12,13]$. Indeed, MMP9 inhibition or gene silencing further blocks trophoblast invasion in vitro [14]. As trophoblasts under preeclampsia conditions produce less MMP9, multiple lines of evidence point to an important role for MMP9 in preeclampsia $[9,15,16]$. Interestingly, a recent study showed that MMP9 deficiency in mice caused physiological and placental abnormalities, intrauterine growth restriction, or embryonic death, which are similar to the outcomes observed with human preeclampsia [17]. These findings suggest that MMP9 may play a role in the development of preeclampsia.

$\beta$-catenin and Snail, target molecules of Rac1, are key regulators of cell polarity and invasion $[18,19]$. $\beta$-catenin regulates vital cell events, such as proliferation, migration and differentiation, by acting as a nuclear transcriptional regulator of a wide array of genes [20]. Abnormal regulation of $\beta$-catenin signaling and the subsequent increase in $\beta$-catenin expression have been found to promote cell proliferation and have been implicated in colon carcinogenesis [21]. Furthermore, enhanced Wnt/ $\beta$-catenin signaling has been reported to play a critical role in proper trophoblast, invasion and invasive differentiation [22]. In addition, aberrant accumulation of $\beta$-catenin promotes invasion and migration, as observed for example in oral squamous cell carcinoma cells (OSCC) cells upon enhancing Tcf/Lefmediated transcriptional activity and MMP expression [23]. Snail is a member of a family of zinc finger transcription factors and is aberrantly overexpressed in multiple malignant 
tumours [24-26]. It is positive correlated with tumour invasion, which increase the risk for distant metastases $[27,28]$. Previous studies in human preeclampsia and the rat salt-induced model of preeclampsia found that Snail levels were significantly decreased in total placenta extracts [29]. The literature also suggests that Snail-induced migration and scattering are attenuated by Rac1 inhibition [30]. Most importantly, activation of both Snail and $\beta$-catenin can increase MMP expression and promote migration and invasion [31, 32].

Given the impaired trophoblast invasion in preeclampsia, we hypothesized that the Rac1 mediated-modulation of $\beta$-catenin and Snail activation may contribute to EVT invasion by regulating MMP9 secretion. To explore this hypothesis, we determined the activity of Rac1 and its downstream targets, $\beta$-catenin, Snail and MMP9 in normal gestational tissues and in preeclamptic placental tissues and then examined the effects of the Rac $1 / \beta$-catenin axis and its interactions with Snail and MMP9 on the invasion and migration of HTR-8/SVneo cells.

\section{Materials and Methods}

\section{Subjects and sample collection}

The experiment was approved by the Clinical Research Ethics Committee of the Second Hospital of Shandong University, and informed consent was obtained from all participants according to the Declaration of Helsinki. A total of 117 subjects in different trimesters of pregnancy were recruited from outpatient and inpatient services at the Department of Obstetrics and Gynecology, the Second Hospital of Shandong University, Jinan, from June 2010 to December 2014. There were 25 first trimester subjects at 6-9 weeks of gestation (average age: $28.5 \pm 3.8$ years), 25 term gestation subjects at 37-40 weeks of gestation (average age: $27.9 \pm 3.3$ years). 67 patients with preeclampsia at $37-40$ weeks of gestation. The preeclampsia cohort included 37 women with mild preeclampsia (average age: $28.9 \pm 3.25$ years) and 30 with severe forms of preeclampsia (average age: $26.9 \pm 2.8$ years). The trophoblasts samples from the first trimesters of normal pregnancies were collected during induced abortion procedures, while the normal pregnancy and preeclampsia placental tissues from the third trimester were obtained by cesarean section. The freshly obtained placenta samples were immediately snap-frozen immediately fixed with $10 \%$ formalin overnight and embedded in paraffin for immunohistochemistry studies.

The diagnosis criteria for preeclampsia were systolic blood pressure $\geqq 140 \mathrm{mmHg}$, diastolic blood pressure $\geqq 90 \mathrm{mmHg}$, presence of proteinuria in a 24-h urinary sample exceeding $300 \mathrm{mg}$, a urine protein: creatinine ratio $>0.3$, and $\geqq 30 \mathrm{mg} / \mathrm{dl}$ protein in a random urine sample $(1+$ reaction on a standard urine dipstick). Severe preeclampsia was defined as blood pressure $\geqq 160 / 110 \mathrm{mmHg}$ on 2 occasions at least $6 \mathrm{~h}$ apart while the patient is on bed rest, proteinuria $\geq 2+$ in 2 random urine samples collected at least $4 \mathrm{~h}$ apart, headache, visual disturbances, upper abdominal pain, serum creatinine and transaminase elevation, foetalgrowth restriction, or thrombocytopenia [33]. Pregnant patients with renal disease, hypertension before pregnancy, placental abruption or placenta praevia, anaemia or other haematological disease, gestational diabetes, or foetal distress syndrome were excluded from our study.

\section{Cell culture}

HTR-8/SVneo cells, an immortalized cell line that is a well-established model of first trimester human trophoblasts, were grown in RPMI- 1640 media supplemented with $10 \%$ foetal bovine serum (FBS) (HyClone, USA), $100 \mathrm{U} / \mathrm{ml}$ penicillin, and $100 \mathrm{ng} / \mathrm{ml}$ streptomycin at $37 \mathrm{C}$ in $5 \% \mathrm{CO}_{2}$ as previously described [34]. (Gibco BRL/Invitrogen, USA).

\section{Reagents}

Antibodies specific for Snail were purchased from Santa Cruz Biotechnology, Inc. (Santa Cruz, USA). Anti-MMP9 and anti-Rac1 antibodies were obtained from Abcam (Cambridge, USA). Anti-active- $\beta$-catenin and anti-snail antibodies were purchased from Cell Signaling Technology, Inc. (Danvers, USA). Anti- $\beta$-actin antibodies were obtained from Novus Biologicals, Inc. (Littleton, CO, USA). The shRNAs were synthesized by Cyagen Bioscience Inc. (Guangzhou, China). The Rac1 Activation Assay Kit was purchased from NewEast Biosciences, Inc. (Malvern, USA). Secondary antibodies were from Sigma-Aldrich, Inc. (Saint Louis, USA). 


\section{Transfection of Rac1 small interfering RNA}

ShRNAs oligonucleotides were designed with the following sequences: Rac1 shRNA, 3'-CGC AAA CAG ATG TGT TCT TAA-5'; and negative Cont-shRNA, 3'-GCG CGC TTT GTA GGA TTCG-5'. HTR8/SVneo cells were reverse transfected using Lipofectamine TM 2000 (Invitrogen, USA) according to the manufacturer's instructions. One day before transfection, trypsinized HTR-8/SVneo cells diluted to 80,000 cells/well in 1.5 $\mathrm{ml}$ of growth medium (RPMI 1640 with serum but without antibiotics) were seeded into 12-well plates. After a 24-h incubation with Rac1 shRNA or Cont-shRNA, the cells were incubated for another $48 \mathrm{~h}$ and then harvested for Rac1 mRNA and protein expression analysis by real-time reverse transcription PCR and Western blot, respectively.

\section{RNA extraction and Quantitative real-time PCR}

Real-time reverse transcription PCR was used to detect the gene expression in HTR-8/ SVneo cells and placental tissues. Total RNA was extracted from the HTR-8/SVneo cells or placental tissues using the RNAiso Plus reagent (Takara, Dalian, China) according to the manufacturer's instructions. In brief, aliquots of total RNA (1.0 $\mu \mathrm{g}$ each) from each sample were reverse transcribed into cDNA according to the instructions of PrimeScript RT Reagent Kit (Perfect Real Time) instructions (Takara, Dalian, China).

The following specific primers were designed: Rac1: sense, 5'-TCC TGT AGT CGC TTT GCCTA-3', antisense, $5^{\prime}$-GTC CCA CGC TGT ATT CTCTA-3'; $\beta$-actin: sense, $5^{\prime}$-TGA CGT GGA CAT CCG CAAAG-3', antisense, 5'-CTG GAA GGT GGA CAG CGAGG-3', and MMP9: sense, 5'-TTG ACA GCG ACA AGA AGTGG-3', antisense, $5^{\prime}$ CGG CAC TGA GGA ATG ATCTA-3'.

After reverse transcription of total RNA, cDNA was used as a template for the PCR reactions using genespecific primer pairs, which were purchased from Sangon Biotech Co., Ltd (Shanghai, China). Amplification was performed using SYBR Premix Ex Taq Kit (Takara, Dalian, China) and a LightCycler 480 Real-Time PCR system (Roche Applied Science, F. Hoffmann-La Roche Ltd, Pleasanton, CA, USA).

The programme included pre-incubation $\left(95^{\circ} \mathrm{C}\right.$ for $\left.5 \mathrm{~min}\right)$, amplification $\left(40\right.$ cycles of $95^{\circ} \mathrm{C}$ for 10 $\mathrm{s}, 60^{\circ} \mathrm{C}$ or $10 \mathrm{~s}$, and $72^{\circ} \mathrm{C}$ for $10 \mathrm{~s}$ ), melting curve analysis $\left(95^{\circ} \mathrm{C}\right.$ for $5 \mathrm{~s}, 65^{\circ} \mathrm{C}$ for $1 \mathrm{~min}$, and temperature increases in set increments up to $\left.97^{\circ} \mathrm{C}\right)$ ) and cooling $\left(40^{\circ} \mathrm{C}\right.$ for $\left.30 \mathrm{~s}\right)$. The specificity of the PCR products can be verified by melting curve analysis or $\mathrm{T}_{\mathrm{m}}$ calling in the LightCycler 480 Real-Time PCR system; the Tm was calculated and each gene showed a single peak in the melting curve for each gene. Untreated HTR-8/ SVneo cells or placental tissues in early pregnancy were used as calibrator samples.

\section{Western blot analysis}

Total and nuclear proteins were extracted from the placental tissues and HTR-8/SVneo cells using CelLytic MT Cell Lysis Reagent and NuCLEAR Extraction Kit (Sigma, USA).

The protein concentrations were determined using the Bradford assay (Bio-Rad Laboratories, USA). The absorbance was measured at $595 \mathrm{~nm}$ using a Beckman DU-640 spectrophotometer (Beckman, Fullerton, CA). Equal amounts of protein lysate $(30 \mu \mathrm{g})$ were separated by $10 \%$ SDS-PAGE and were wettransferred onto a polyvinylidene fluoride (PVDF) membrane (Millipore, USA). Immunoblotting was performed using primary antibodies against the following target proteins: rabbit polyclonal to Rac1 (1 $\mu \mathrm{g} / \mathrm{ml})$, active $\beta$-catenin $(1 \mu \mathrm{g} / \mathrm{ml})$, MMP9 $(1 \mu \mathrm{g} / \mathrm{ml})$ and Snail $(5 \mu \mathrm{g} / \mathrm{ml})$; mouse monoclonal to $\beta$-actin (1 $\mu \mathrm{g} / \mathrm{ml})$. Membranes were incubated at room temperature for $2 \mathrm{~h}$ with each primary antibody. After three washes with PBS ( $9.0 \mathrm{~g} / \mathrm{L} \mathrm{NaCl}, 0.224 \mathrm{~g} / \mathrm{L} \mathrm{KCl}, 3.58 \mathrm{~g} / \mathrm{L} \mathrm{Na}_{2} \mathrm{HPO}_{4} \cdot 12 \mathrm{H}_{2} \mathrm{O}$, and $\left.0.28 \mathrm{~g} / \mathrm{L} \mathrm{NaH}_{2} \mathrm{PO}_{4}{ }^{*} 2 \mathrm{H}_{2} \mathrm{O}\right)$, the membranes were incubated with horseradish peroxidase (HRP) conjugated secondary antibody $(1: 10,000)$ for $1 \mathrm{~h}$ at room temperature. Specific bands were detected using the ECL system (Amersham Biosciences, USA) and the Bio-Rad electrophoresis image analyser (Bio-Rad, USA). LabWorks image analysis software was used to analyse the $\beta$-actin band intensity as an internal control. All data were normalized to control or early pregnancy samples ( set to 1 ), and the results are presented as the mean \pm SEM.

\section{Measurement of Rac1 activity}

The active form of Rac1 is bound to GTP, which can be evaluated using a pull-down assay for Rac1-GTP (NewEast Biosciences, USA). Briefly, placental tissues and HTR-8/SVneo cells were homogenized in lysis buffer in the presence of protease and phosphatase inhibitors and centrifuged at 12,000×g for $15 \mathrm{~min}$ on ice. The lysates were then cleared by centrifugation, and the protein content was estimated using the Bio-Rad protein assay. To analyse for active Rac1 levels, each sample was adjust the volume to $1 \mathrm{ml}$ with $1 \times$ Assay/ 


\section{Cellular Physiology Cell Physiol Biochem 2016;38:1319-1332 \begin{tabular}{l|l} 
and Biochemistry 10.1159/000443076 & $\begin{array}{l}\text { (c) 2016 The Author(s). Published by S. Karger AG, Basel } \\
\text { www.karger.com/cpb }\end{array}$ \\
\hline
\end{tabular}}

Fan et al.: Rac1 Promotes Invasion of Trophoblast Cells

Lysis Buffer and incubated with an anti-active Rac1 monoclonal antibody bound to protein $A / G$ agarose beads for $1 \mathrm{~h}$ at $4^{\circ} \mathrm{C}$. The GTP-bound form of Rac 1 in the pull-down samples was separated by centrifugation precipitated $(5000 \times \mathrm{g})$ at $4^{\circ} \mathrm{C}$ for $1 \mathrm{~min}$, precipitated, subjected to SDS-PAGE as described in the previous paragraph, and detected using anti-Rac1 antibodies and ECL.

\section{Transwell invasion assay}

The transwell Matrigel invasion assay was performed as previously described, with minor modifications [35]. Briefly, $50 \mu \mathrm{l}$ of diluted 1:4 Matrigel (1:4 dilution; BD Biosciences, USA) in serum-free RPMI 1640 medium was added to the upper chambers of 24-well transwell inserts (BD Biosciences, USA) and incubated at $37^{\circ} \mathrm{C}$ overnight to enable solidification. HTR-8/SVneo cells transfected with Rac1 shRNA or Cont-shRNA or pretreated with or without the $\beta$-catenin inhibitor IWP-2 (Santa Cruz, USA) were harvested from culture plates at a density of $5 \times 10^{4}$ cells $/ \mathrm{ml}$. The cells were then plated into the upper chambers of transwell inserts coated with or without Matrigel. The lower chambers were filled with $600 \mu \mathrm{L}$ of RPMI 1640 medium containing $10 \%$ FBS.

After incubation at $37^{\circ} \mathrm{C}$ for $24 \mathrm{~h}$, the upper side of the membranes the filters were scrubbed with cotton swabs to remove the non-invading cells, and the membranes were subsequently fixed in $4 \%$ paraformaldehyde (Sigma-Aldrich, USA) and stained with $0.2 \%$ crystal violet (Sigma-Aldrich, USA). The number of invading cells, in 10 random fields on the underside of the membrane were counted by using an inverted microscope at a magnification of $\times 200$ (Olympus, USA).

\section{Immunohistochemistry and immunofluorescence}

Placental tissue sections $(6 \mathrm{~mm})$ were de-waxed and hydrated, and endogenous peroxides were quenched with $0.3 \% \mathrm{H}_{2} \mathrm{O}_{2}$ for $30 \mathrm{~min}$. Then, heat-induced antigen retrieval was conducted and the slides were incubated with the anti-MMP9 antibody $(1 \mu \mathrm{g} / \mathrm{ml}))$ overnight at $4^{\circ} \mathrm{C}$. After washing, the sections were incubated with HRP-labeled goat anti-rabbit immunoglobulin for $1 \mathrm{~h}$ at room temperature. Staining was completed by incubation with diaminobenzidine chromogen solution (DAB) solution (Santa Cruz, USA) and counterstaining with Harris's haematoxylin (Sigma-Aldrich, USA); the sections were then dehydrated and mounted. Corresponding concentrations of anti-IgG served as non-specific controls. Photographs were taken with a microscope (Leica Microsystems, Germany). Cells under different conditions were plated into different 6-well plates and fixed in $4 \%$ paraformaldehyde for $20 \mathrm{~min}$, followed by $0.3 \%$ Triton X-100 for $10 \mathrm{~min}$. After pre-incubation with $10 \%$ foetal calf serum to block nonspecific binding, cells were individually incubated with primary antibodies against MMP9 $(1 \mu \mathrm{g} / \mathrm{ml})$ at $4^{\circ} \mathrm{C}$ overnight. To visualize the primary antibodies, cells were stained with DyLight 549-conjugated secondary antibodies (1:200) and 4, 6-diamidino-2-phenylindole (DAPI) to visualize the nuclei. Images were observed and captured using an inverted phase/fluorescence microscope (Leica Microsystems GmbH, Germany).

\section{Statistical analysis}

Experiments were performed at least three times. The data are presented as the mean \pm s.d. Data was analyzed using SPSS 13.0 software. Statistical significance was assessed using ANOVA and the LSD-t-test, and $\mathrm{P}<0.05$ was considered to be statistically significant.

\section{Results}

\section{Activation of Rac1 in human placenta}

To determine the role of Rac1 in placental formation and development, we detected the activation of Rac1 at different gestational stages. GTP-Rac1 was examined in villus tissues from early pregnancy and placental tissues from term pregnancy. GTP-Rac1 levels were highest in early pregnancy and significantly reduced in term pregnancy. Lower levels were observed in preeclampsia than in normal term pregnancy; in particular, the level in severe preeclampsia was markedly lower than that in mild preeclampsia $(\mathrm{P}<0.01$, Fig. $1 \mathrm{~A}$ and $1 \mathrm{~B})$. No remarkable alterations in total Rac1 expression were observed at different gestational stages and preeclampsia ( $\mathrm{P}>0.05$, Fig. 1C and 1D). 

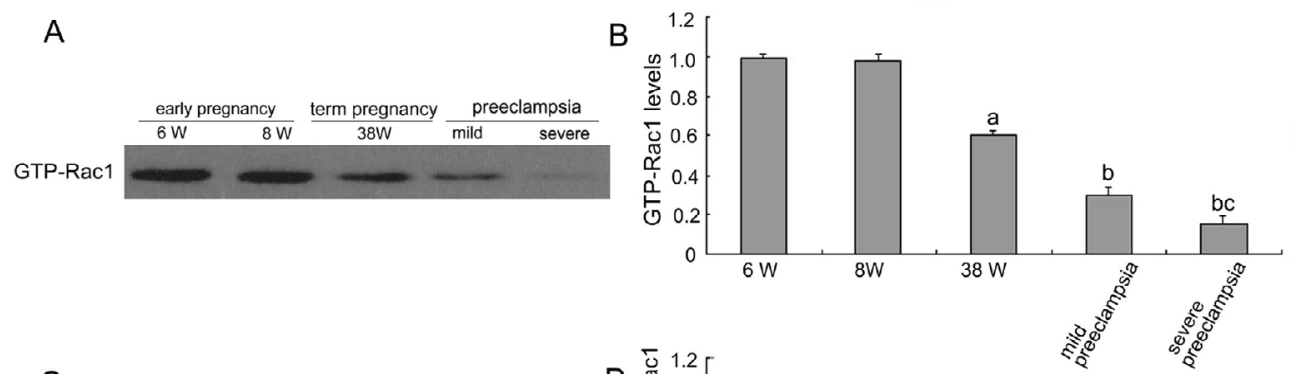

C $\frac{\text { early pregnancy }}{6 W} \frac{\text { term pregnancy }}{38 W} \frac{\text { preeclampsia }}{\text { mild }}$

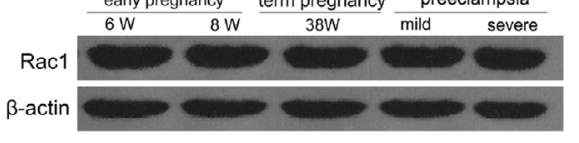

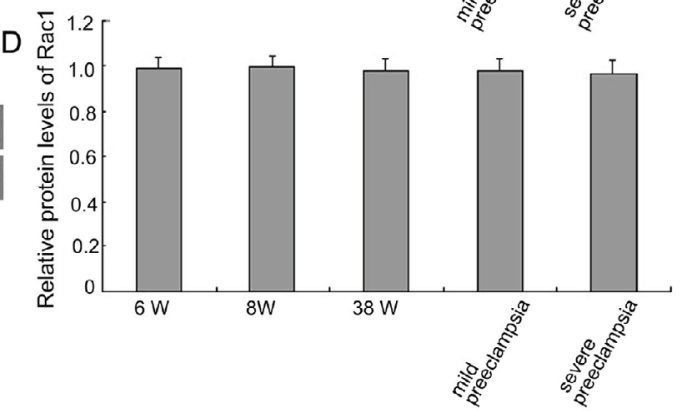

Fig. 1. The Rac1 activation assessment in the human placenta. (A) and (B) Rac1 activity was measured by Rac1-GTPase pull-down assay and Western blotting assay. The GTP-Rac1 level exhibited a remarkable down-regulation in term pregnancy than early pregnancy $(\mathrm{P}<0.01)$. Lower GTP-Rac1 level was found in mild preeclampsia and severe preeclampsia and GTP-Rac1 level of severe preeclampsia was significantly lower compared with mild preeclampsia ( $\mathrm{P}<0.01)$. (C) and (D) No remarkable alterations of total Rac1 expression appeared in different gestational stages and preeclampsia $(\mathrm{P}>0.05)$. (B) and (D) are generated by densitometry analysis. a) $\mathrm{P}<0.01$ vs. early pregnancy, b) $\mathrm{P}<0.01$ vs. term pregnancy, c) $\mathrm{P}<0.01$ vs. mild preeclampsia.

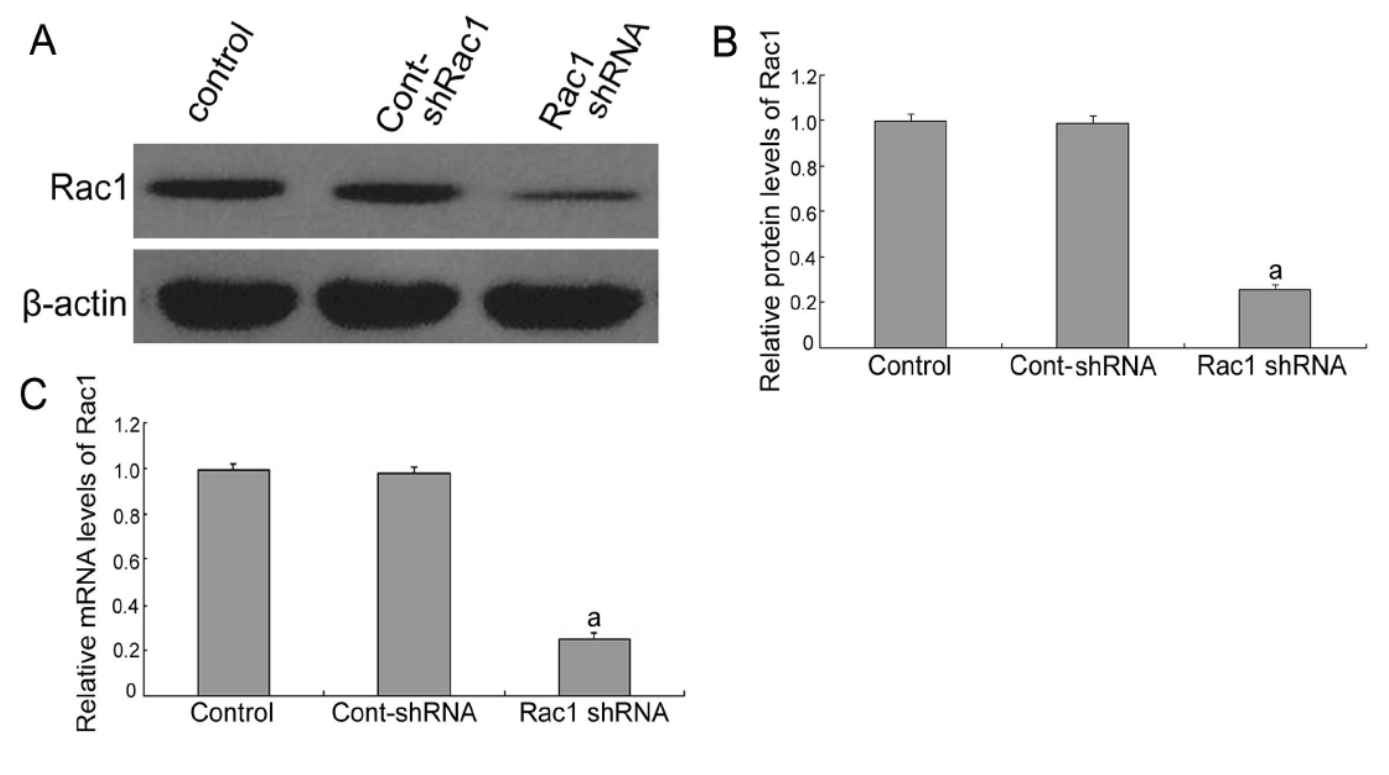

Fig. 2. The effects of gene knockdown by Rac1 shRNA on Rac1 expression in HTR-8/SVneo cells by Western blot (A and B) and real-time reverse transcriptase PCR (C). (B) is generated by densitometry analysis. Rac1 mRNA and protein expression were not significantly altered in HTR-8/SVneo cells cultured in Cont-shRNA for $24 \mathrm{~h}$ compared to normal condition; a 24-h incubation with Rac1 shRNA markedly reduced the expression of Rac1. a) P $<0.01$ vs. normal control. 

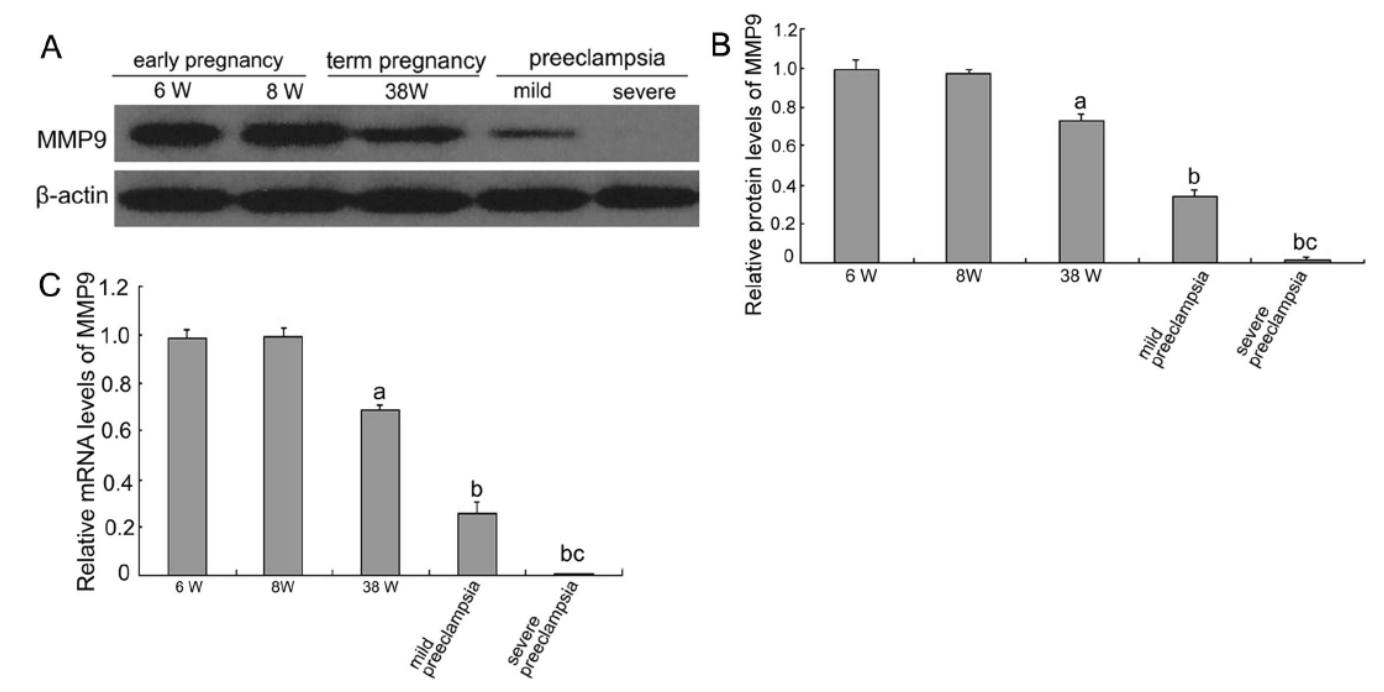

Fig. 3. The expression of MMP9 in the human placenta by Western blot (A and B) and real-time reverse transcriptase PCR (C). (B) is generated by densitometry analysis.The levels of protein and mRNA ofMMP9 in term pregnancy were significantly higher compared with early pregnancy $(\mathrm{P}<0.01)$. They were noticeably dropped in preeclampsia than term pregnancy $(\mathrm{P}<0.01)$. a) $\mathrm{P}<0.01$ vs. early pregnancy, b) $\mathrm{P}<0.01$ vs. term pregnancy, c) $\mathrm{P}<0.01$ vs. mild preeclampsia.

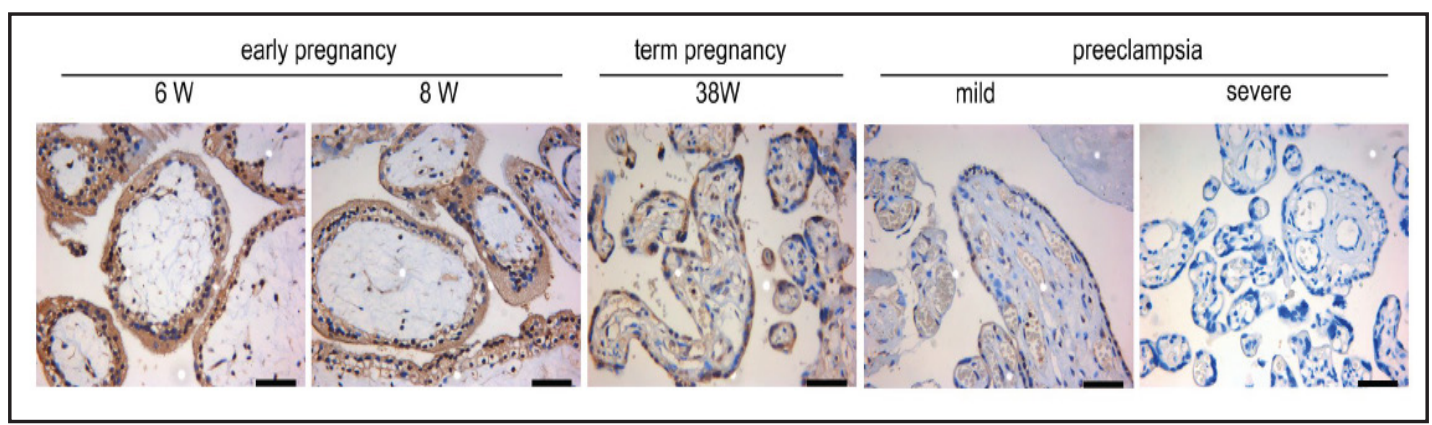

Fig. 4. Immunohistochemistry staining revealed the expression of MMP9 in the human placenta. MMP9 are mainly localized in the cytoplasm of placenta trophoblasts. MMP9 expression was an increased staining in early pregnancy, but reduced in preeclampsia compared with term pregnancy and it also diminished in severe preeclampsia in comparison with mild preeclampsia. Scale bar stands for $50 \mu \mathrm{m}$.

\section{Expression of MMP9 in the human placenta and HTR-8/SVneo cells}

To better evaluate Rac1 regulation of trophoblast invasion, we utilized vectors that express Rac1 shRNA to transfect HTR-8/SVneo cells which have an EVT phenotype. Realtime PCR and Western blot showed that Rac1 mRNA and protein expression in HTR-8/SVneo cells transfected with Rac1 shRNA was dramatically attenuated compared with controltransfected cells $(\mathrm{P}<0.01$, Fig. 2). Placental villus samples exhibited significantly diminished MMP9 protein and mRNA expression in term pregnancy compared to early pregnancy ( $\mathrm{P}<0.01$, Fig. 3 ) and reduced expression in preeclampsia compared to normal term pregnancy $(\mathrm{P}<0.01)$. Compared to mild preeclampsia, expression levels were lower in severe preeclampsia $(\mathrm{P}<0.01)$. The effects were further confirmed by immunohistochemistry; MMP9 was observed in the cytoplasm of placental trophoblasts in term pregnancy, and MMP9 levels were relatively attenuated compared to early pregnancy, moreover it was found significantly decreased in preeclampsia (Fig. 4).

\section{KARGER}



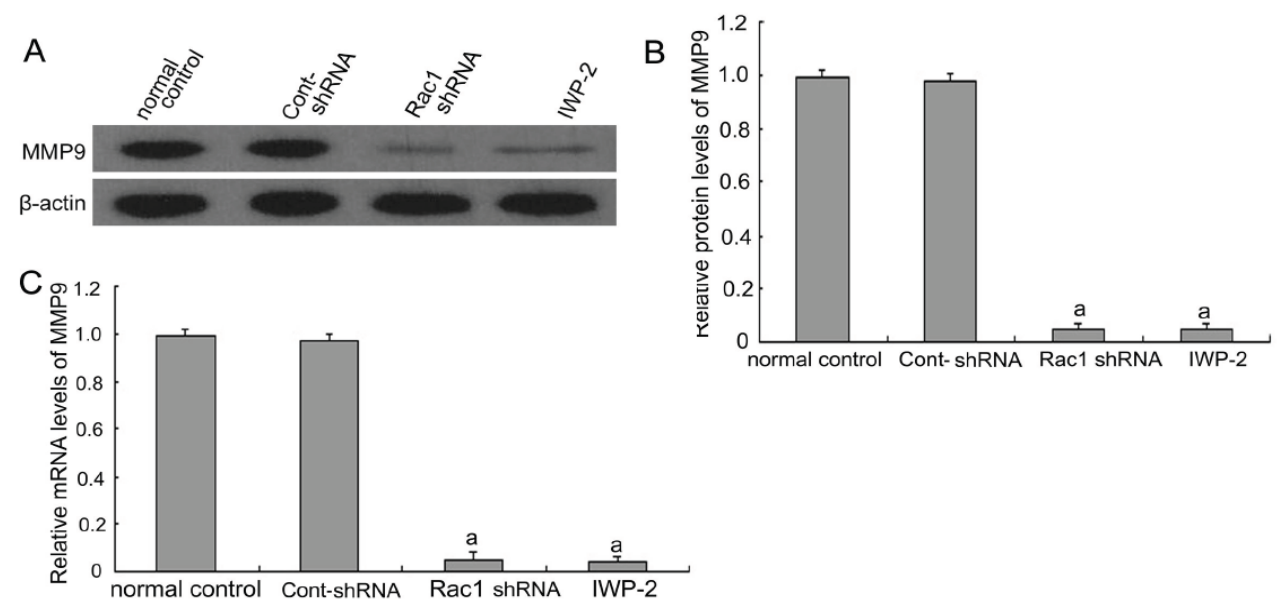

Fig. 5. The expression of MMP9 in HTR-8/SVneo cells by Western blot (A and B) and real-time reverse transcriptase PCR (C). (B) is generated by densitometry analysis. In HTR-8/SVneo cells, transfected with Rac1 shRNA or treated with beta-catenin inhibitor-IWP-2 (5 $\mu \mathrm{M})$ for $24 \mathrm{~h}$, MMP9 protein and mRNA expression reduced compared to normal, which shows significant differences $(\mathrm{P}<0.01)$. a) $\mathrm{P}<0.01$ vs. normal control.

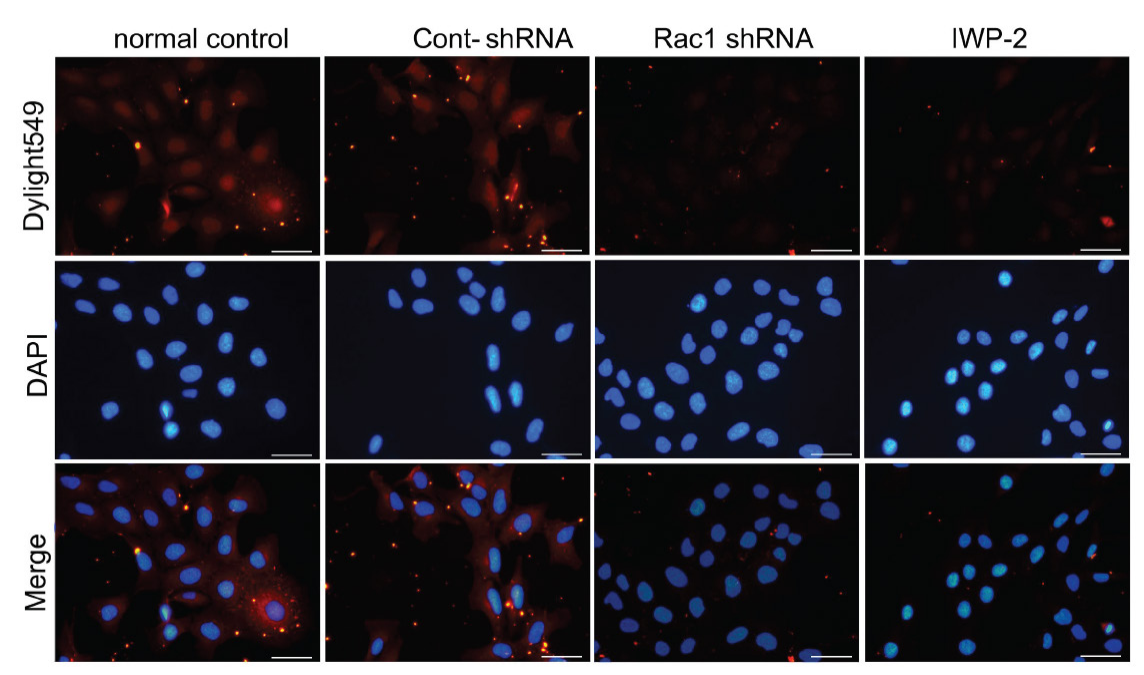

Fig. 6. Immunofluorescence staining revealed the expression of MMP9 in HTR-8/SVneo cells. MMP9 was stained in the HTR-8/SVneo; transfection with Rac1 shRNA or pretreatment with IWP-2 led to a decreased staining of MMP9. To visualize the primary antibodies, cells were stained with DyLight 549-conjugated secondary antibodies, and double stained with 4' 6-diamidino-2-phenylindole (DAPI) to visualize the nuclei (MMP9 is stained with red and the cell nuclei with blue fluorescence). Scale bar stands for $20 \mu \mathrm{m}$.

In experiments using HTR-8/SVneo cells cultured in vitro, we discovered that MMP9 protein and mRNA expression significantly declined after transfection with Rac1 shRNA compared to normal control transfection $(\mathrm{P}<0.01$, Fig. 5). Immunofluorescence further indicated that under normal conditions, MMP9 was expressed in the HTR-8/SVneo cells, but efficient silencing of Rac1 led to weaker expression of MMP9 in cells transfected with Rac1 shRNA and treated with $\beta$-catenin inhibitor IWP-2 (Fig. 6).

Rac1 is essential for HTR-8/SVneo cells invasion

We succeeded in detecting HTR-8/SVneo cell migration and invasion; the invasion of cells transfected with Rac1 shRNA was significantly weaker than that of control and Cont- 


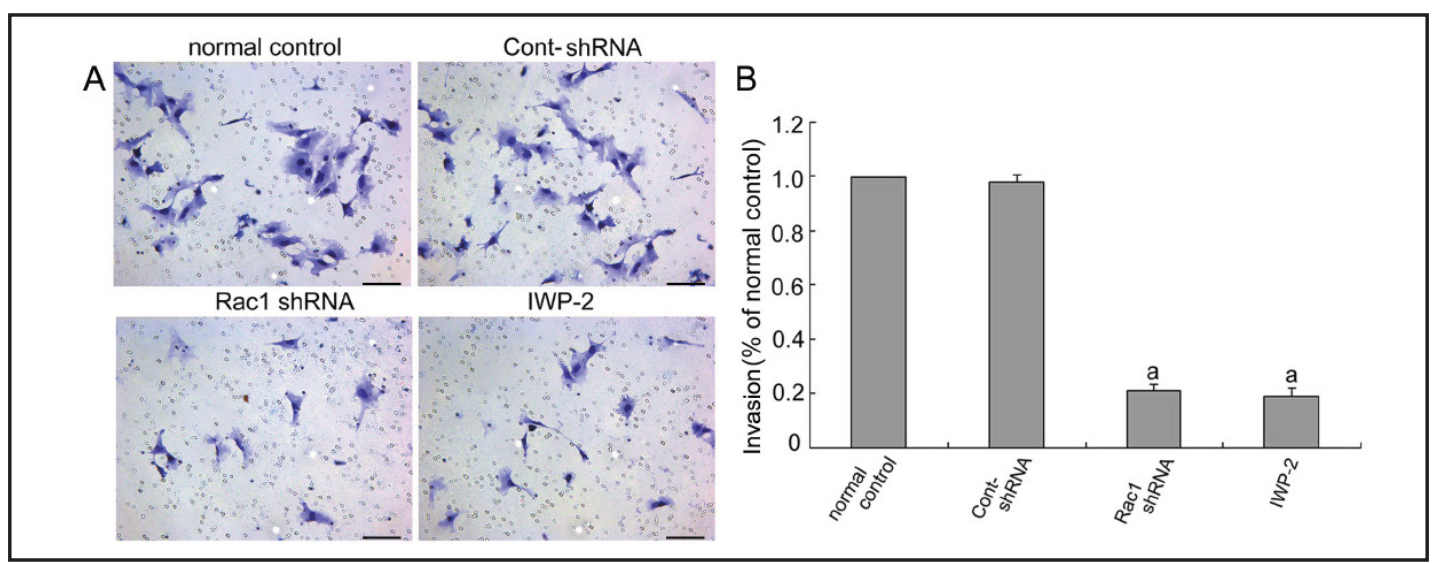

Fig. 7. Transwell migration assay analysis of HTR-8/SVneo cells invasion (A) and the results are represented as means of invasion percentage (\%) \pm s.d (B). After transfected with Rac1 shRNA, Cont-shRNA or pretreated with IWP-2, the cells were cultured for an additional $24 \mathrm{~h}$. Invaded cells were fixed with $4 \%$ paraformaldehyde, followed by staining with crystal violet. The invasion ability of cells transfected with Rac1 shRNA and pretreated with IWP-2 was lower than normal control, showing significant differences. a) $\mathrm{P}<0.01$ vs. normal control. Scale bar stands for $40 \mu \mathrm{m}$.

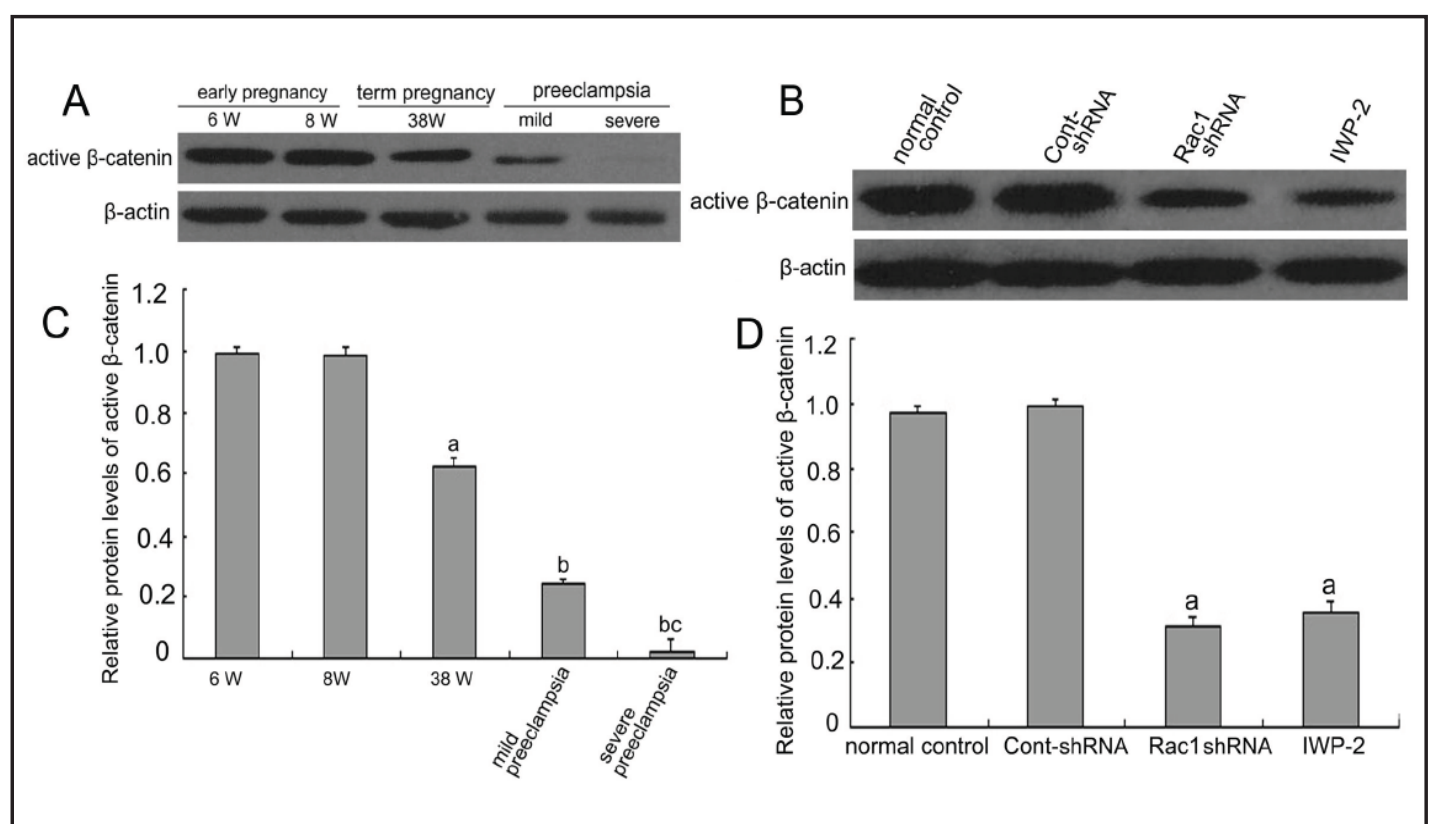

Fig. 8. The expression of dephosphorylated- $\beta$-catenin in the human placenta (A) and HTR-8/SVneo cells (B) by Western blot. (C) and (D) are generated by densitometry analysis. The nuclear protein were extracted from the placental tissues and HTR-8/SVneo cells by nuclear extract isolation and immunoblotted using antibodies against dephosphorylated- $\beta$-catenin. (A) The expressions of dephosphorylated- $\beta$-catenin exhibited remarkable down-regulation in term pregnancy than early pregnancy $(\mathrm{P}<0.01)$. Decreased expressions were found in mild preeclampsia and severe preeclampsia than term pregnancy. The expression in severe preeclampsia was significantly lower than mild preeclampsia $(\mathrm{P}<0.01)$. a) $\mathrm{P}<0.01$ vs. early pregnancy, b) $\mathrm{P}<0.01$ vs. term pregnancy, c) $\mathrm{P}<0.01$ vs. mild preeclampsia. (B) The down-regulated expressions of dephosphorylated- $\beta$-catenin were determined in the cells pretreated with Rac1shRNA or IWP-2 compared with normal control. a) $\mathrm{P}<0.01$ vs. normal control.

shRNA-transfected cells ( $\mathrm{P}<0.01$, Fig. 7). No significant differences of invasion between normal HTR-8/SVneo cells and transfected Cont-Rac1 cells were observed (P > 0.05, Fig. 7). 


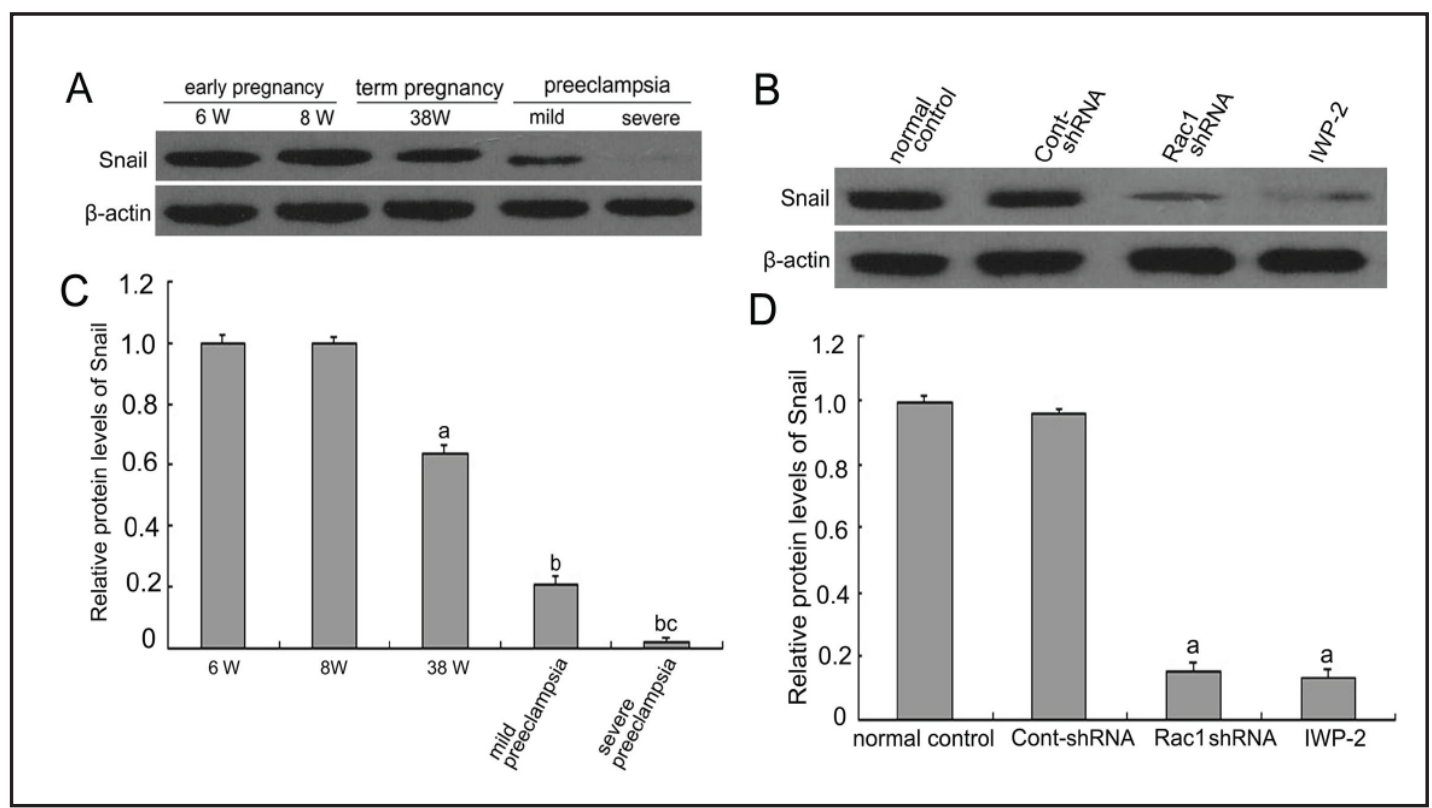

Fig. 9. The expression of Snail in the human placenta (A) and HTR-8/SVneo cells (B) by Western blot. (C) and (D) are generated by densitometry analysis. (A) The nuclear protein were extracted from the placental tissues and HTR-8/SVneo cells by nuclear extract isolation and immunoblotted using antibodies against Snail. The expressions of Snail exhibited remarkable down-regulation in early pregnancy $(\mathrm{P}<0.01)$. Decreased expressions were found in mild preeclampsia and severe preeclampsia than term pregnancy. The expression in severe preeclampsia was significantly lower than mild preeclampsia ( $<<0.01)$. a) $\mathrm{P}<0.01$ vs. early pregnancy, b) $\mathrm{P}<0.01$ vs. term pregnancy, c) $\mathrm{P}<0.01$ vs. mild preeclampsia. (B) The down-regulated expressions of Snail were determined in the cells pretreated with Rac1 shRNA or IWP-2 compared with normal control. a) $\mathrm{P}<0.01$ vs. normal control.

\section{$\beta$-catenin expression is regulated by Rac1}

The levels of dephosphorylated $\beta$-catenin which represents the active form gradually decreased with the gestational weeks, and they were decreased in term pregnancy compared with early pregnancy. The expression was lower in preeclampsia compared with normal term pregnancy; in particular, severe preeclampsia showed a great decrease than mild preeclampsia ( $\mathrm{P}<0.01$, Fig. $8 \mathrm{~A}$ and $8 \mathrm{C}$ ). To confirm whether $\beta$-catenin participates in Rac1regulated trophoblast invasion, we further utilized HTR-8/SVneo cells transfected with Rac1 shRNA. $\beta$-catenin activation was remarkably decreased in Rac1 shRNA-transfected cells compared with normal control ( $\mathrm{P}<0.01$, Fig. 8B and 8D). To support our findings, we treated HTR-8/SVneo cells with IWP-2, a $\beta$-catenin inhibitor that increases cytosolic $\beta$-catenin phosphorylation and degradation to decrease nuclear $\beta$-catenin levels. Pretreatment with IWP-2 $(5 \mu \mathrm{M})$ for $24 \mathrm{~h}$ notably inhibited $\beta$-catenin activation $(\mathrm{P}<0.01$, Fig. 8B and 8D). Moreover, MMP9 protein and mRNA expression levels were significantly reduced compared with the normal control ( $\mathrm{P}<0.01$, Fig. 5). Likewise, HTR-8/SVneo cell invasion was decreased compared with the normal control condition ( $\mathrm{P}<0.01$, Fig. 7).

\section{Snail expression is regulated by Rac1}

Our results revealed that the transcription factor Snail gradually decreased with an increase in gestational weeks and was remarkably down-regulated in preeclampsia; in particular, Snail expression was lower in severe preeclampsia than in mild preeclampsia ( $P<0.01$, Fig. 9A and 9C). Moreover, in HTR-8/SVneo cells transfected with Rac1 shRNA or pretreated with IWP-2, there was a significant down-regulation of Snail expression in the nuclei compared with control cells and transfected cells ( $<<0.01$, Fig. 9B and 9D). 


\section{Discussion}

The invasion of trophoblast cells into the maternal uterine decidua and myometrium is critical for normal placentation, establishment of pregnancy and maintenance of foetal growth in humans. Several growth factors and cytokines are implicated in trophoblast invasion [36], but the underlying invasion regulatory mechanisms are not fully understood. Therefore, it is of great significance to study the mechanisms affecting trophoblast invasion to elucidate uncovering the pathogenesis of preeclampsia.

Like tumour cells, invasiveness is a characteristic of trophoblasts that enables them to invade into the decidua and myometrium and then remodel the uterine spiral arteries to maintain placental blood supply; this is crucial for normal placental development [37]. Compared to normal pregnancy tissues, our research discovered that Rac1 expression declined in preeclampsia placental tissues. This evidence, along with the previous observation that Rac1 activity was significantly lower in women with preeclampsia and HELLP [6-8], supports the view that Rac1 potentially contributes to placental development. Furthermore, the present study showed the activity of Rac1 at different gestational stages and under preeclampsia conditions; these changes corresponded with the down-regulation of trophoblast invasion, suggesting that Rac1 may be involved in the regulation of trophoblast invasion to prevent shallow placental implantation.

Several studies have answered a longstanding question regarding the role of MMP9 in preeclampsia. Previous studies cultured trophoblasts isolated from preeclampsia placenta tissues in vitro and determined that MMP9 secretion and infiltration were remarkably decreased [38]. Other data imply that MMP9 deficiency causes placental abnormalities in mice, and these abnormalities share similar features to those in preeclampsia. MMP9-null mouse embryos exhibit deficiencies in trophoblast differentiation and invasion shortly after implantation, along with intrauterine growth restriction or embryonic death [17]. Thus, the regulation of MMP9 is vital for trophoblast infiltration and is key for placental implantation. Accordingly, our results indicated that MMP9 gradually decreased with the gestational weeks and was lower in preeclampsia tissues compared with normal term pregnancy tissues. There is evidence that Rac1 modulates transforming growth factor- $\beta 1$-mediated epithelial cell plasticity and MMP9 production in transformed keratinocytes [39]. Thus, we investigated the potential role of the Rac1 axis and its interactions with MMP9 in trophoblast invasion. Our data showed that Rac1 shRNA resulted in efficient and specific down-regulation of Rac1 at the mRNA and protein levels, and this down-regulation further diminished MMP9 levels, which might inhibit the invasion of HTR-8/SVneo cells. Therefore, we postulate a potential notion that Rac1 may facilitate trophoblast invasion by promoting MMP9 expression.

Snail is associated with numerous diseases and is involved in cell differentiation and embryonic development. Studies have argued that Snail up-regulation caused by hypoxiainducible factor- $1 \alpha$ in cultured human first trimester villous explants reduces E-cadherin expression, which influences cell-cell interactions and activates an invasion programme [40]. Data are suggested that down-regulation by internal and external factors may contribute to the development of human preeclampsia by disrupting essential stages of placental development [29]. In this study, we have demonstrated that human placentas tissues from patients with preeclampsia contain lower levels of the transcription factor Snail compared with normal term placenta tissues, and Snail expression changed in agreement with Rac1 expression. At the transcriptional level, Snail is regulated by many signaling pathways. Likewise, a previous study reported that Snail-induced migration and scattering of pancreatic cancer cells were attenuated by Rac1 inhibition [30]. In our further study, we observed that Snail nuclear localization was inhibited by transfection with Rac1 shRNA, indicating that Rac1 may promote trophoblast cell invasion and placental implantation by increasing Snail transcriptional activity.

$\beta$-catenin, a multifunctional intracellular protein that contains 781 amino acids, is an important adhesion factor and transcription factor. Nuclear accumulation of $\beta$-catenin promotes theinvasiveEVT differentiation in the human placentathatcontributestotrophoblast

\section{KARGER}


hyperplasia and invasion [41]. Defective activation of $\beta$-catenin during placentation (day 40) in bovine somatic cell nuclear transfer (SCNT)-derived foetuses compromised foetomaternal attachment and exchange and foetal survival, resulting in pregnancy loss [42]. Moreover, recent studies have demonstrated that $\beta$-catenin is significantly decreased in preeclamptic placental tissues compared to normal placental controls and that its activation significantly promotes the invasion of HTR-8/SVneo cells $[43,44]$. Taking into account the initial results, reduced $\beta$-catenin expression in the placenta is expected to influence its transcriptional activity and thus the expression of $\beta$-catenin response genes, thereby controlling trophoblast invasion. In accordance with previous reports, our study showed that the nuclear expression of dephosphorylated $\beta$-catenin decreased with gestational weeks, was significantly weaker in preeclampsia samples than in term pregnancy samples, and was lower in severe preeclampsia tissues compared with mild preeclampsia tissues.

Previous studies confirmed that Rac1 is a critical regulator of $\beta$-catenin activation and nuclear translocation $[45,46]$, it therefore plays important roles in $\beta$-catenin nuclear localization and $\beta$-catenin-dependent transcriptional activation $[45,47]$.

In the current study, knockdown of Rac1 by Rac1 shRNA led to a notable repression of $\beta$-catenin dephosphorylation and HTR8/SVneo cell invasion, suggesting that Rac1 may play a pivotal role in modulating $\beta$-catenin nuclear translocation and thus participate in the regulation of trophoblast invasion. Recent research has shown that the $\beta$-catenin-mediated increase in Snail transcriptional activity is associated with the epithelial-mesenchymal transition in renal carcinoma [48]. In this study, we observed reduced Snail protein levels in HTR-8/SVneo cells transfected with Rac1 shRNA or pretreated with IWP-2, which enhances cytosolic $\beta$-catenin phosphorylation and degradation and thus decreases nuclear $\beta$-catenin levels. Taken together, these data suggest that Rac1 may trigger Snail transcription directly through $\beta$-catenin nuclear translocation and be consequently involved in trophoblast invasion. Furthermore, overexpression of Snail enhanced the invasion of human ovarian cancer H0-8910PM cells transfected with a human Snail recombinant plasmid, while Snailspecific shRNA remarkably decreased MMP mRNA and protein expression as well as invasive activities [49]. Therefore, based on previous studies and our research, we speculated that Rac1 and $\beta$-catenin might be critical upstream effectors that trigger Snail translocation and transcriptional activity, which promotes trophoblast invasion and embryo implantation, possibly via Snaill-mediated activation of MMP9 expression.

Collectively, we demonstrated that Rac1 gene in trophoblast regulates $\beta$-catenin in trophoblasts, thereby, affecting Snail activation and MMP9 expression and further facilitating EVT cell invasion.

\section{Acknowledgments}

This study was supported by the National Science Foundation of China (Grant No. 81272858).

\section{Disclosure Statement}

The authors declare no conflict of interest.

\section{References}

1 Pauli JM, Repke JT: Preeclampsia: Short-term and long-term implications. Obstet Gynecol Clin North Am 2015;42:299-313.

2 Pennington KA, Schlitt JM, Jackson DL, Schulz LC, Schust DJ: Preeclampsia: Multiple approaches for a multifactorial disease. Dis Model Mech 2012;5:9-18.

3 Mack NA, Whalley HJ, Castillo-Lluva S, Malliri A: The diverse roles of rac signaling in tumorigenesis. Cell Cycle 2011;10:1571-1581.

4 Feng M, Bao Y, Li Z, Li J, Gong M, Lam S, Wang J, Marzese DM, Donovan N, Tan EY, Hoon DS, Yu Q: Rasal2 activates rac1 to promote triple-negative breast cancer progression. J Clin Invest 2014;124:5291-5304. 


\section{Cellular Physiology Cell Physiol Biochem 2016;38:1319-1332 \begin{tabular}{l|l|l}
\hline DOI: 10.1159/000443076 & (c) 2016 The Author(s). Published by S. Karger AG, Basel \\
\hline
\end{tabular} and Biochemistry Published online: March 24, $2016 \quad$ www.karger.com/cpb}

Fan et al.: Rac1 Promotes Invasion of Trophoblast Cells

5 Chen QY, Zheng Y, Jiao DM, Chen FY, Hu HZ, Wu YQ, Song J, Yan J, Wu LJ, Lv GY: Curcumin inhibits lung cancer cell migration and invasion through rac1-dependent signaling pathway. J Nutr Biochem 2014;25:177-185.

6 Hannke-Lohmann A, Pildner von Steinburg S, Dehne K, Benard V, Kolben M, Schmitt M, Lengyel E: Downregulation of a mitogen-activated protein kinase signaling pathway in the placentas of women with preeclampsia. Obstet Gynecol 2000;96:582-587.

$7 \quad$ Nicola C, Lala PK, Chakraborty C: Prostaglandin e2-mediated migration of human trophoblast requires rac1 and cdc42. Biol Reprod 2008;78:976-982.

8 Liu S, Cui H, Li Q Zhang L, Na Q, Liu C: Rhogdi2 is expressed in human trophoblasts and involved in their migration by inhibiting the activation of rac1. Biol Reprod 2014;90:88.

9 Lalu MM, Xu H, Davidge ST: Matrix metalloproteinases: Control of vascular function and their potential role in preeclampsia. Front Biosci 2007;12:2484-2493.

10 Staun-Ram E, Goldman S, Gabarin D, Shalev E: Expression and importance of matrix metalloproteinase 2 and 9 (mmp-2 and -9) in human trophoblast invasion. Reprod Biol Endocrinol 2004;2:59.

11 Kessenbrock K, Plaks V, Werb Z: Matrix metalloproteinases: Regulators of the tumor microenvironment. Cell 2010;141:52-67.

12 Alexander CM, Hansell EJ, Behrendtsen O, Flannery ML, Kishnani NS, Hawkes SP, Werb Z: Expression and function of matrix metalloproteinases and their inhibitors at the maternal-embryonic boundary during mouse embryo implantation. Development 1996;122:1723-1736.

13 Cohen M, Meisser A, Bischof P: Metalloproteinases and human placental invasiveness: Placenta 2006;27:783-793.

14 Librach CL, Werb Z, Fitzgerald ML, Chiu K, Corwin NM, Esteves RA, Grobelny D, Galardy R, Damsky $\mathrm{CH}$, Fisher SJ: 92-kd type iv collagenase mediates invasion of human cytotrophoblasts. J Cell Biol 1991;113:437-449.

15 Graham CH, McCrae KR: Altered expression of gelatinase and surface-associated plasminogen activator activity by trophoblast cells isolated from placentas of preeclamptic patients. Am J Obstet Gynecol 1996;175:555-562.

16 Jia RZ, Ding GC, Gu CM, Huang T, Rui C, Wang YX, Lu Q: Cdx2 enhances htr-8/svneo trophoblast cell invasion by altering the expression of matrix metalloproteinases. Cell Physiol Biochem 2014;34:628-636.

17 Plaks V, Rinkenberger J, Dai J, Flannery M, Sund M, Kanasaki K, Ni W, Kalluri R, Werb Z: Matrix metalloproteinase-9 deficiency phenocopies features of preeclampsia and intrauterine growth restriction. Proc Natl Acad Sci U S A 2013;110:11109-11114.

18 Hall A: The cytoskeleton and cancer. Cancer Metastasis Rev 2009;28:5-14.

19 Hughes SC, Fehon RG: Understanding erm proteins--the awesome power of genetics finally brought to bear. Curr Opin Cell Biol 2007;19:51-56.

20 Goldstein B, Takeshita H, Mizumoto K, Sawa H: Wnt signals can function as positional cues in establishing cell polarity. Dev Cell 2006;10:391-396.

21 Zhen T, Dai S, Li H, Yang Y, Kang L, Shi H, Zhang F, Yang D, Cai S, He Y, Liang Y, Han A: Macc1 promotes carcinogenesis of colorectal cancer via beta-catenin signaling pathway. Oncotarget 2014;5:3756-3769.

22 van der Horst PH, Wang Y, van der Zee M, Burger CW, Blok LJ: Interaction between sex hormones and wnt/beta-catenin signal transduction in endometrial physiology and disease. Mol Cell Endocrinol 2012;358:176-184.

23 Iwai S, Yonekawa A, Harada C, Hamada M, Katagiri W, Nakazawa M, Yura Y: Involvement of the wnt-betacatenin pathway in invasion and migration of oral squamous carcinoma cells. Int J Oncol 2010;37:10951103.

24 Nieto MA: The snail superfamily of zinc-finger transcription factors. Nat Rev Mol Cell Biol 2002;3:155-166.

25 Miyoshi A, Kitajima Y, Kido S, Shimonishi T, Matsuyama S, Kitahara K, Miyazaki K: Snail accelerates cancer invasion by upregulating $\mathrm{mmp}$ expression and is associated with poor prognosis of hepatocellular carcinoma. Br J Cancer 2005;92:252-258.

26 Roy HK, Smyrk TC, Koetsier J, Victor TA, Wali RK: The transcriptional repressor snail is overexpressed in human colon cancer. Dig Dis Sci 2005;50:42-46.

27 Come C, Magnino F, Bibeau F, De Santa Barbara P, Becker KF, Theillet C, Savagner P: Snail and slug play distinct roles during breast carcinoma progression. Clin Cancer Res 2006;12:5395-5402.

28 Elloul S, Elstrand MB, Nesland JM, Trope CG, Kvalheim G, Goldberg I, Reich R, Davidson B: Snail, slug, and smad-interacting protein 1 as novel parameters of disease aggressiveness in metastatic ovarian and breast carcinoma. Cancer 2005;103:1631-1643. 
29 Fedorova L, Gatto-Weis C, Smaili S, Khurshid N, Shapiro JI, Malhotra D, Horrigan T: Down-regulation of the transcription factor snail in the placentas of patients with preeclampsia and in a rat model of preeclampsia. Reprod Biol Endocrinol 2012;10:15.

30 Shields MA, Krantz SB, Bentrem DJ, Dangi-Garimella S, Munshi HG: Interplay between beta1-integrin and rho signaling regulates differential scattering and motility of pancreatic cancer cells by snail and slug proteins. J Biol Chem 2012;287:6218-6229.

31 Mikami S, Katsube K, Oya M, Ishida M, Kosaka T, Mizuno R, Mukai M, Okada Y: Expression of snail and slug in renal cell carcinoma: E-cadherin repressor snail is associated with cancer invasion and prognosis. Lab Invest 2011;91:1443-1458.

32 Crampton SP, Wu B, Park EJ, Kim JH, Solomon C, Waterman ML, Hughes CC: Integration of the betacatenin-dependent wnt pathway with integrin signaling through the adaptor molecule grb2. PLoS ONE 2009;4:e7841.

33 Acog practice bulletin: Diagnosis and management of preeclampsia and eclampsia. Number 33, january 2002. Obstet Gynecol 2002;99:159-167.

34 Graham CH, Hawley TS, Hawley RG, MacDougall JR, Kerbel RS, Khoo N, Lala PK: Establishment and characterization of first trimester human trophoblast cells with extended lifespan. Exp Cell Res 1993;206:204-211.

35 Dong Z, Xu X, Du L, Yang Y, Cheng H, Zhang X, Li Z, Wang L, Li J, Liu H, Qu X, Wang C: Leptin-mediated regulation of $\mathrm{mt1}-\mathrm{mmp}$ localization is kif1b dependent and enhances gastric cancer cell invasion. Carcinogenesis 2013;34:974-983.

36 Guzeloglu-Kayisli O, Kayisli UA, Taylor HS: The role of growth factors and cytokines during implantation: Endocrine and paracrine interactions. Semin Reprod Med 2009;27:62-79.

37 Soundararajan R, Rao AJ: Trophoblast 'pseudo-tumorigenesis': Significance and contributory factors. Reprod Biol Endocrinol 2004;2:15.

38 Campbell S, Rowe J, Jackson CJ, Gallery ED: Interaction of cocultured decidual endothelial cells and cytotrophoblasts in preeclampsia. Biol Reprod 2004;71:244-252.

39 Santibanez JF, Kocic J, Fabra A, Cano A, Quintanilla M: Rac1 modulates tgf-beta1-mediated epithelial cell plasticity and mmp9 production in transformed keratinocytes. FEBS Lett 2010;584:2305-2310.

40 Arimoto-Ishida E, Sakata M, Sawada K, Nakayama M, Nishimoto F, Mabuchi S, Takeda T, Yamamoto T, Isobe A, Okamoto Y, Lengyel E, Suehara N, Morishige K, Kimura T: Up-regulation of alpha5-integrin by e-cadherin loss in hypoxia and its key role in the migration of extravillous trophoblast cells during early implantation. Endocrinology 2009;150:4306-4315.

41 Pollheimer J, Loregger T, Sonderegger S, Saleh L, Bauer S, Bilban M, Czerwenka K, Husslein P, Knofler M: Activation of the canonical wingless/t-cell factor signaling pathway promotes invasive differentiation of human trophoblast. Am J Pathol 2006;168:1134-1147.

42 Kohan-Ghadr HR, Smith LC, Arnold DR, Murphy BD, Lefebvre RC: Aberrant expression of e-cadherin and beta-catenin proteins in placenta of bovine embryos derived from somatic cell nuclear transfer. Reprod Fertil Dev 2012;24:588-598.

43 Zhang Z, Li H, Zhang L, Jia L, Wang P: Differential expression of beta-catenin and dickkopf-1 in the third trimester placentas from normal and preeclamptic pregnancies: A comparative study. Reprod Biol Endocrinol 2013;11:17.

44 Zhuang B, Luo X, Rao H, Li Q Shan N, Liu X, Qi H: Oxidative stress-induced c/ebpbeta inhibits beta-catenin signaling molecule involving in the pathology of preeclampsia. Placenta 2015;36:839-846.

45 Esufali S, Bapat B: Cross-talk between rac1 gtpase and dysregulated wnt signaling pathway leads to cellular redistribution of beta-catenin and tcf/lef-mediated transcriptional activation. Oncogene 2004;23:82608271.

46 Wu X, Tu X, Joeng KS, Hilton MJ, Williams DA, Long F: Rac1 activation controls nuclear localization of betacatenin during canonical wnt signaling. Cell 2008;133:340-353.

47 Buongiorno P, Pethe VV, Charames GS, Esufali S, Bapat B: Rac1 gtpase and the rac1 exchange factor tiam1 associate with wnt-responsive promoters to enhance beta-catenin/tcf-dependent transcription in colorectal cancer cells. Mol Cancer 2008;7:73.

48 Gnemmi V, Bouillez A, Gaudelot K, Hemon B, Ringot B, Pottier N, Glowacki F, Villers A, Vindrieux D, Cauffiez C, Van Seuningen I, Bernard D, Leroy X, Aubert S, Perrais M: Muc1 drives epithelial-mesenchymal transition in renal carcinoma through wnt/beta-catenin pathway and interaction with snail promoter. Cancer Lett 2014;346:225-236.

49 Sun L, Lin P, Qin Z, Liu Y, Deng LL, Lu C: Hypoxia promotes ho-8910pm ovarian cancer cell invasion via snail-mediated mt1-mmp upregulation: Exp Biol Med (Maywood) 2015;240:1434-1445. 